\title{
puentes gemelos
}

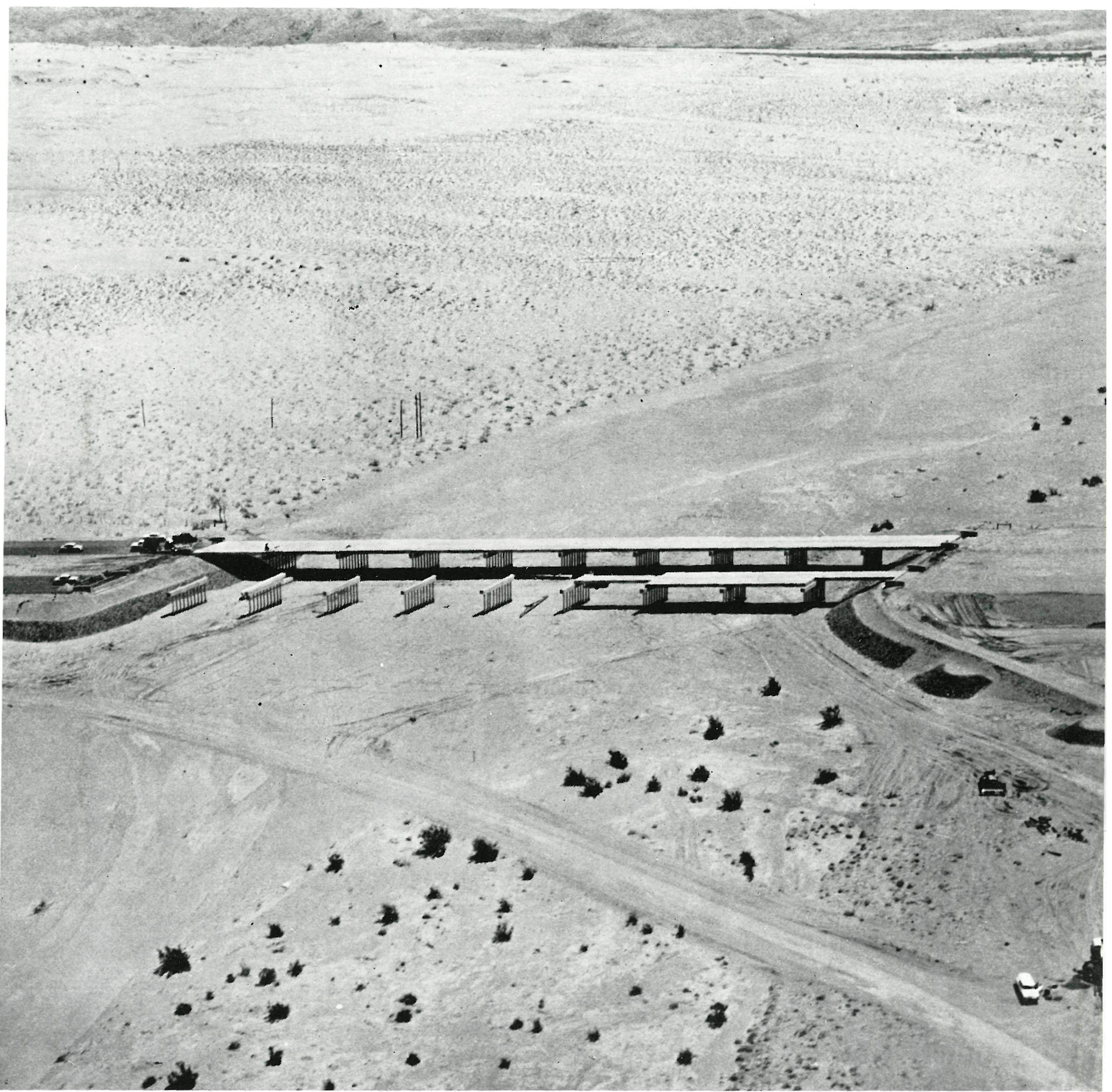

$562 \cdot 44$

\section{río Salado NUEVO MEXICO}




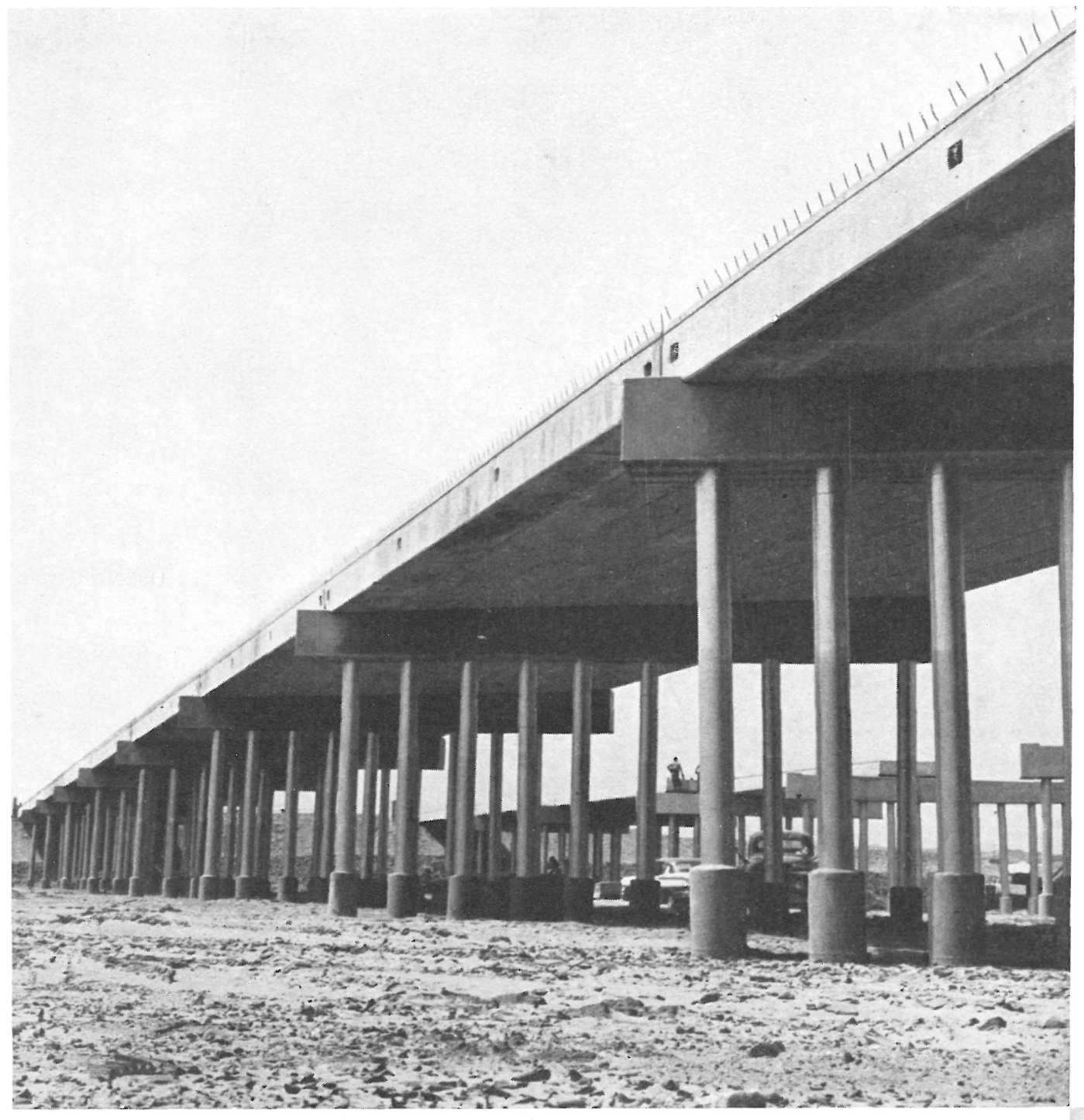

Recientemente, el Estado de Nuevo Méjico acaba de construir un puente para carretera que, por estar ésta dividida en dos partes independientes, de dos bandas de circulación cada una, se han tenido que construir dos estructuras gemelas, paralelas, que salvan el río Salado.

El puente es una obra de fábrica de la carretera provincial o interestados que se halla situada a unos $96 \mathrm{~km}$ de la ciudad de Alburquerque, en el ramal que va de esta aglomeración a la de El Paso, ya en territorio mejicano.

El río Salado, en realidad, es una gran cañada que drena las aguas de una cuenca de unos 3.000 kilómetros cuadrados.

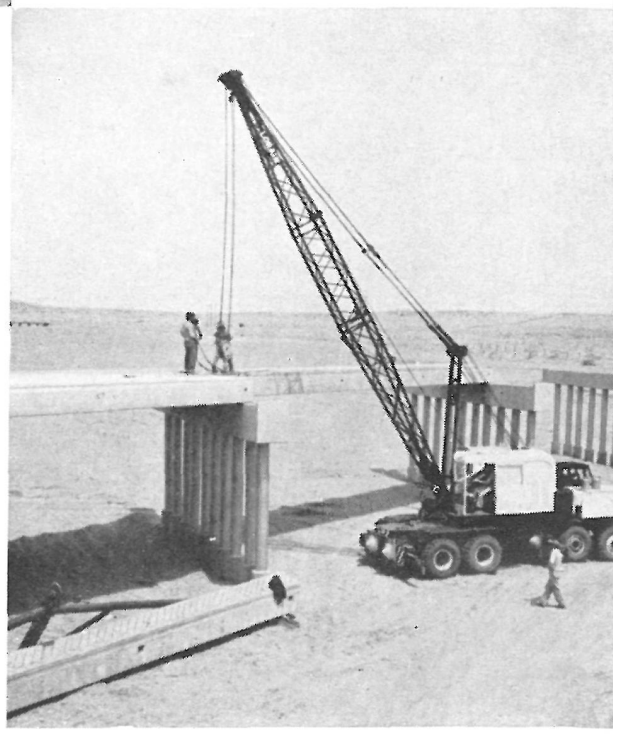




\section{planta de pilas}

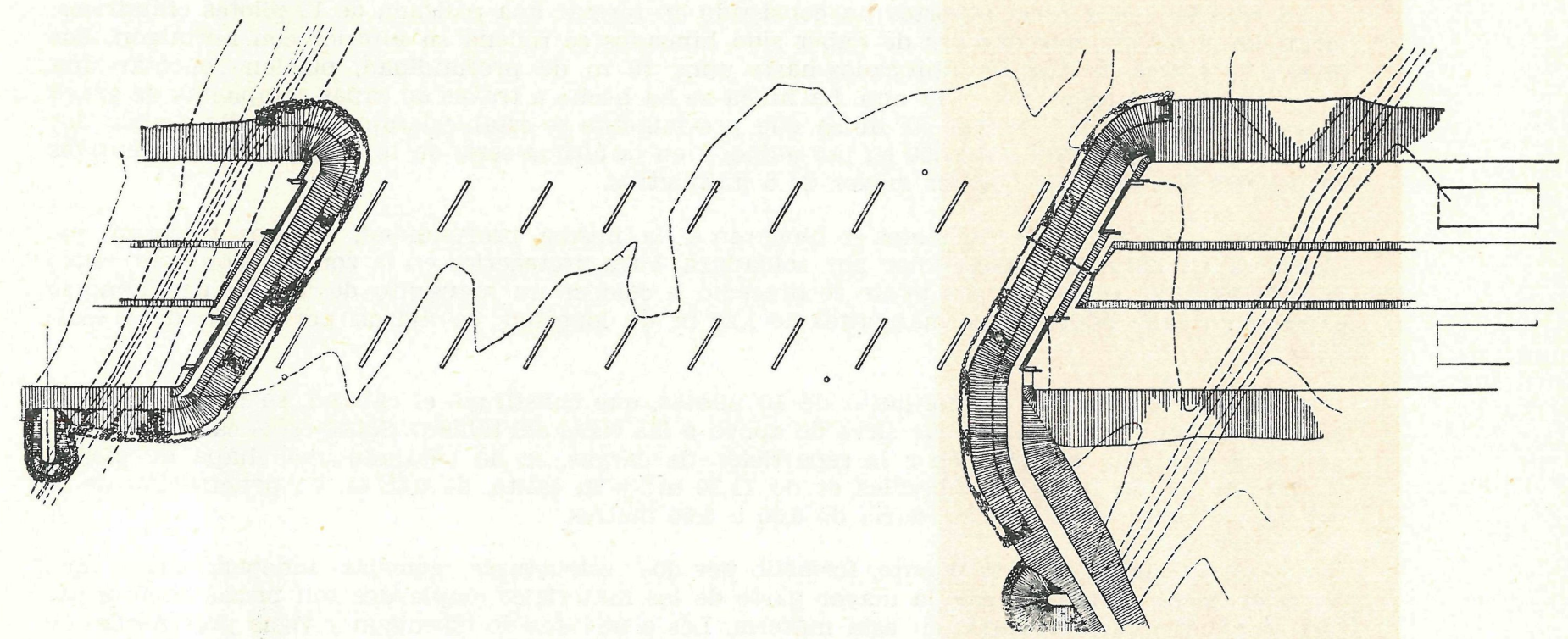

Aunque su curso se halla seco la mayor parte del año, su régimen está íntimamente ligado a los períodos de lluvias y a la accidentalidad de los mismos, ya que algunos días los caudales del río alcanzan volúmenes de gran consideración. El curso de la cañada es amplio y poco encauzado, lo que motiva que las aguas lo desborden y se extiendan sobre las márgenes circundando extensas zonas próximas.

Para protegerse contra las pronunciadas erosiones, se han construído piedraplenes en los estribos y machones de protección en las márgenes del río. Estos piedraplenes constituyen una especie de gaviones, pues se han recubierto con telas metálicas. Los machones, de corta longitud, penetran en el curso del río formando un cierto ángulo respecto a la alineación de los bordes de las márgenes, lo que permite una protección muy eficaz y favorece se depositen cuerpos sólidos de arrastre aguas abajo de su posición.

Uno de los inconvenientes más pronunciados de esta obra ha sido el tipo y forma que debía darse a los soportes, pues se trataba de apoyar el puente sobre un fondo del lecho del río que presentaba potentes capas poco apropiadas para resistir los empujes locales, así como los trastornos que los arrastres y erosiones podrían motivar.

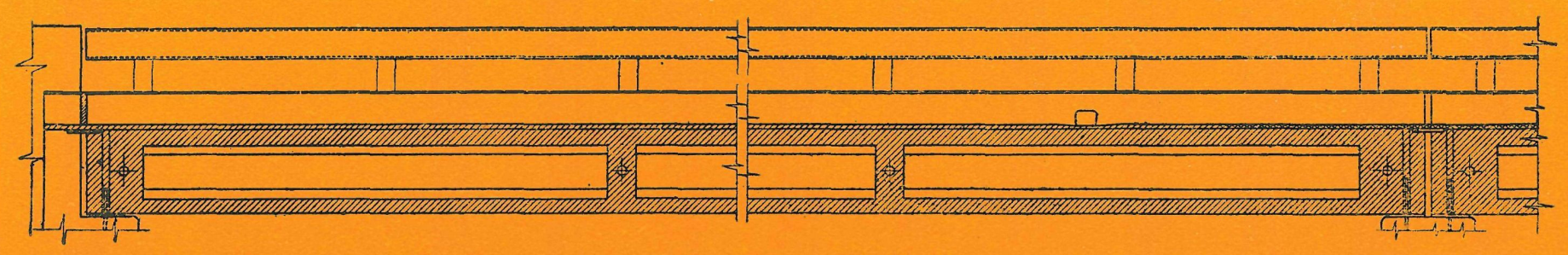

\section{sección longitudinal}

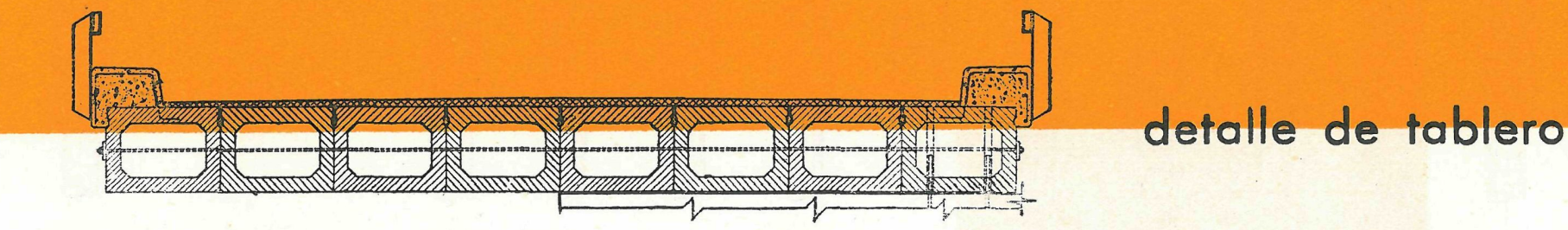

\section{sección transversal}


La solución para estos soportes ha consistido en formar una palizada de 10 pilotes cilíndricos, metálicos y huecos, que después de haber sido hincados se rellena su interior con hormigón. Los pilotes de $0,30 \mathrm{~m}$ de diámetro, hincados hasta unos $10 \mathrm{~m}$ de profundidad, pueden soportar una carga de 40 a 50 toneladas cada uno. La hinca se ha hecho a través de capas compactas de grava y arena, siguiendo las normas de hinca que previamente se establecieron. El martillo o pilón debía dar una energía de unos $2.000 \mathrm{~kg}$ por golpe, y en la última serie de 10 a 20 golpes consecutivos su penetración no tenía que ser mayor de 5 milímetros.

Debido a que no todos los pilotes se hincaron a la misma profundidad, algunos tuvieron que alargarse en obra, empalmándolos por soldadura. Para protegerlos en la zona de contacto, entre la superficie del suelo y la del pilote se procedió a colocar un manguito de $0,50 \mathrm{~m}$ de diámetro exterior en cada pilote. Estos manguitos de $1,20 \mathrm{~m}$ de longitud, se fijaron por medio de la soldadura.

En la parte superior del conjunto de 10 pilotes, que constituye el cabezal, se hormigonó una carrera de hormigón armado que sirve de apoyo a las vigas dei tablero. Sobre estas carreras, y con objeto de dar más uniformidad a la repartición de cargas, se ha colocado una chapa de plomo. La longitud total de estos cabezales es de $11,30 \mathrm{~m}$; y su canto, de $0,85 \mathrm{~m}$. La penetración de la cabeza del pilote en el cabezal varía de 0,30 a 0,50 metros.

La característica de este puente, formado por dos estructuras gemelas independientes, que salva el río en esviaje, es que la mayor parte de los materiales empieados son piezas prefabricadas en talleres especializados en esta materia. Los elementos de hormigón y vigas pretensadas se encargaron a un constructor, mientras que los pilotes metálicos, cilíndricos, se pasó pedido a una Empresa dedicada a construcciones metálicas.

La longitud total de puente es de $153 \mathrm{~m}$, subdividida en diez tramos rectos de unos $20 \mathrm{~m}$ de luz alguno de ellos. Todos estos tramos se soportan con pilas, formadas con diez pilotes metálicos en línea, y constituyendo palizada. La calzada del puente tiene $8,50 \mathrm{~m}$ de anchura, y subdiviơida en dos bandas de circulación para cada estructura independiente. A los dos lados de la calzada se han construíco los bordillos, dejando $0,45 \mathrm{~m}$ de anchura para el paso de peatones. Las cargas por peso propio, sobrecargas, resistencia y estabilidad han seguido las normas del A. A. S. H. O., H20-S16 establecidas para este tipo de obras.

En los talleres de prefabricación de estas vigas cajón, es decir, de sección hueca, de $0,90 \times 0,70$ metros, de cuyas dimensiones la última representa el canto, se ha tenido especial cuidado en las dosificaciones, armaduras y dimensionado. Las vigas, de las que se iban tomando probetas cilíndricas para comprobar la resistencia del material, se sometieron a un tratamiento de curado antes de mandarlas a la obra para su montaje.

\section{detalle de pilas}
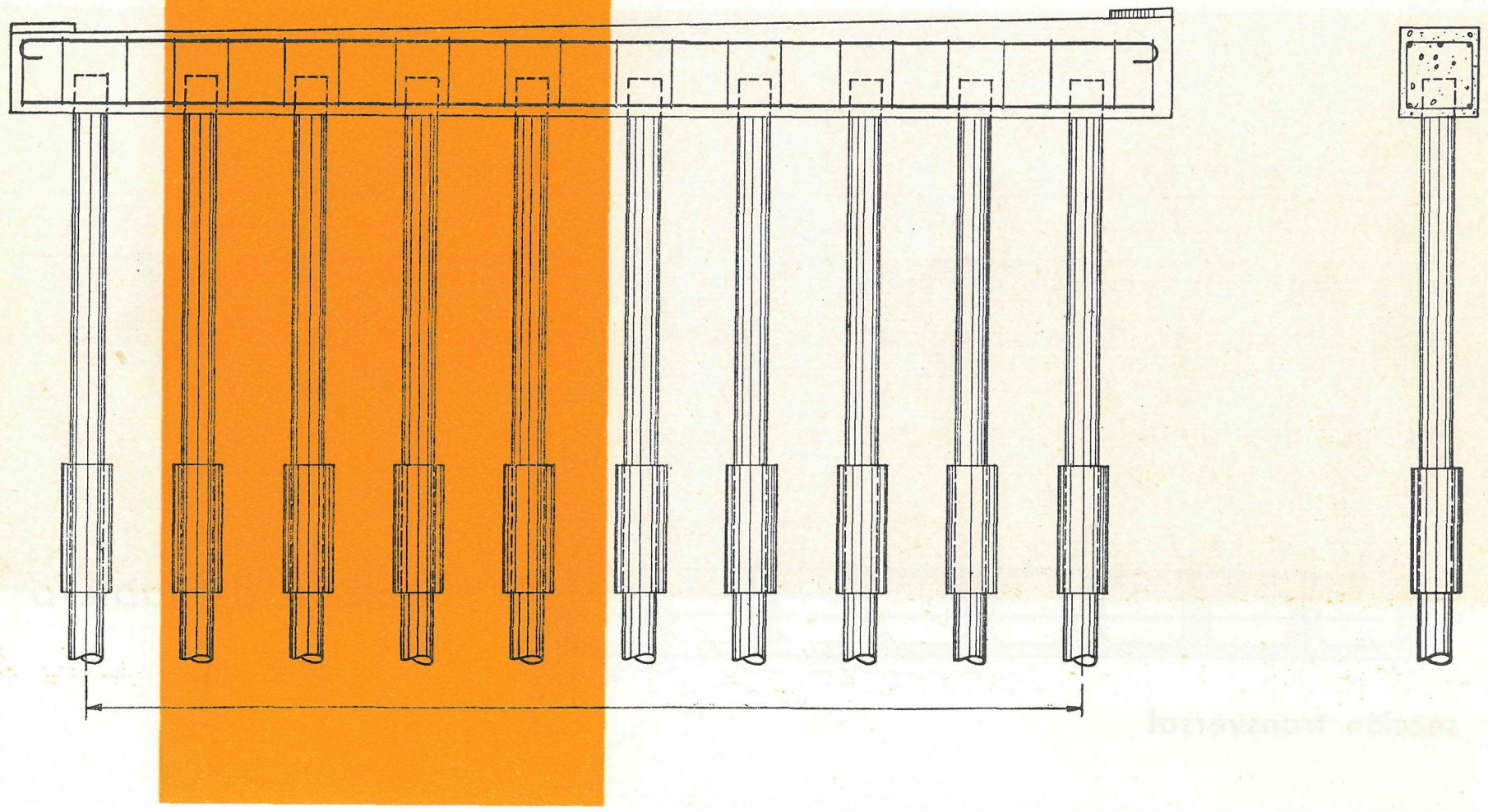

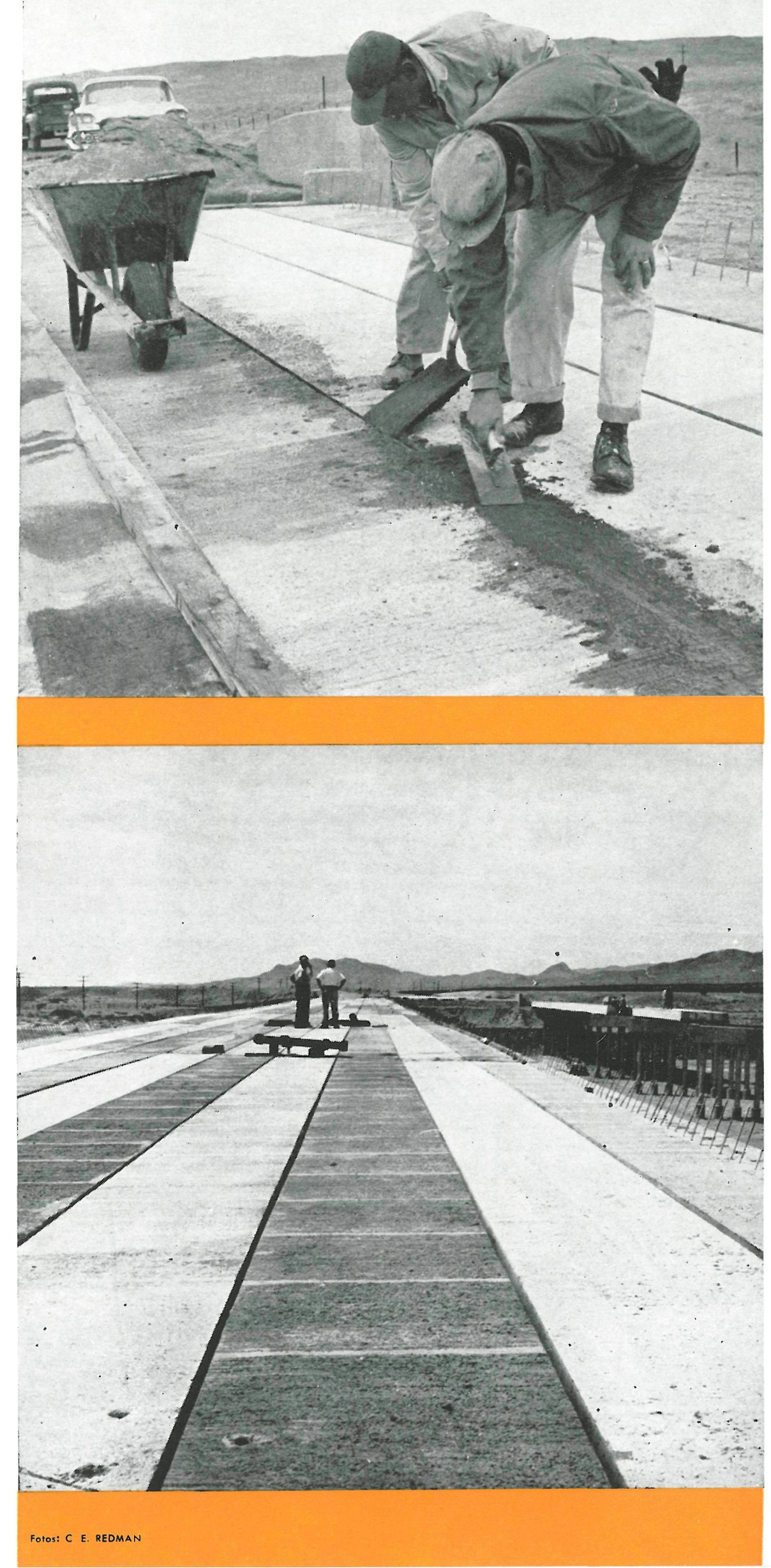

Las vigas tienen, en la parte superior, unos rebajes laterales que, al juntarlas sobre los soportes, dejan una especie de ranura o junta longitudinal que después se rellena con mortero para conseguir su fijación estable. Longitudinalmente, espaciados a unos $5 \mathrm{~m}$, se han dejado unos agujeros de $76 \mathrm{~mm}$ de diámetro para colocar los cables del pretensado transversal.

Las dos vigas laterales constituyen el apoyo de los bordillos y reducido andén. La losa que forma cada uno de estos andenes se subdivide en partes, y entre cada dos de ellas se ha dejado una junta que se rellena con serrín de corcho.

Las vigas principales de sección hueca se apoyan, tanto en estribos como sobre los soportes, por el intermedio de una chapa gruesa, de plomo, que sirve como colchón en la distribución de fuerzas sobre sus apoyos. Entre las extremidades de dos vigas consecutivas se ha formado una junta de $50 \mathrm{~mm}$ de luz, espacio que se ha juzgado suficiente para absorber las deformaciones térmicas que puedan aparecer.

Sobre el tablero constituído por estas vigas se ha colocado la pavimentación o capa bituminosa de $50 \mathrm{~mm}$ de espesor. En los bordillos se han dejado suficientes drenes para el desagüe de aguas de lluvia.

Los métodos constructivos empleados en la ejecución de estas dos estructuras gemelas han consistido en tesar los cables del pretensado transversal por medio de gatos hidráulicos, hormigonar los bordillos en obra, seguir las normas ordinarias en los movimientos de tierras y corrección y protección de las márgenes próximas al puente, pero, en lo que se refiere al transporte de materiales, hinca de pilotes y montaje de las restantes partes del puente, los métodos constructivos se han caracterizado por una gran mecanización. 